\title{
Persistent Pain Following Proplast-Teflon Implants of the Temporomandibular Joint: A Case Report and 35-Year Management Perspective
}

\author{
Roxanne Bavarian (1D ${ }^{1,2}$ \\ Michael E Schatman (iD) 3,4 \\ David A Keith ${ }^{1,2}$ \\ 'Department of Oral and Maxillofacial \\ Surgery, Massachusetts General Hospital, \\ Boston, MA, USA; ${ }^{2}$ Department of Oral \\ and Maxillofacial Surgery, Harvard School \\ of Dental Medicine, Boston, Ma, USA; \\ ${ }^{3}$ Department of Anesthesiology, \\ Perioperative Care, \& Pain Medicine, \\ NYU School of Medicine, New York, NY, \\ USA; ${ }^{4}$ School of Social Work, North \\ Carolina State University, Raleigh, \\ NC, USA
}

\begin{abstract}
Over three decades ago, hundreds of predominantly young women with temporomandibular joint pain and other symptoms were implanted with a prosthetic device composed of Proplast-Teflon that subsequently caused considerable harm, with patients developing chronic pain, dysfunction, and disability. This perspective review presents such a patient who suffered for decades with severe pain despite extensive pharmacotherapy, injection therapy, multiple surgeries, and behavioral health interventions. The details of the origin and subsequent events regarding the use of Proplast-Teflon interpositional implants in the temporomandibular joint are described with resources from several different perspectives. The lessons learned demonstrate failures at the federal, professional, and individual level.

Keywords: Proplast-Teflon, implants, temporomandibular joint surgery, temporomandibular joint replacement, risk management, medicolegal, chronic pain
\end{abstract}

\section{Introduction}

Over three decades ago, a safety event occurred in a small surgical subspecialty that received little coverage in the medical community. Hundreds of predominantly young female patients with temporomandibular joint (TMJ) pain and jaw limitation were harmed by the placement of an implant to replace the meniscus of the TMJ, which led to joint destruction, malocclusion, chronic pain, and other symptoms. ${ }^{1-7}$ The Proplast-Teflon material used in these implants had previously been condemned in the orthopedic literature, and the indications for surgery were suspect. ${ }^{8}$ Now, 35 years later, it would seem useful to review this incident, its genesis, and consequences, and consider what lessons have been learned with the benefit of hindsight and with input from the oral and maxillofacial surgery and medical literature, the courts, government agencies, the insurance industry, the press, patient advocacy groups, and anecdotal patient reports. We present a case of a patient implanted with Proplast-Teflon interpositional implants (PTIPI) and provide a comprehensive review of this incident.

\section{Case Report}

A 55-year-old-woman with a history of multiple TMJ surgeries presented to our clinic with a chief complaint of limited mouth opening and difficulty bringing her teeth together. Her surgical history was significant for the placement of bilateral PTIPIs in the 1980 s, followed by bilateral total joint replacement with Kent-Vitek
Department of Oral and Maxillofacia

Surgery, Massachusetts General Hospital,

55 Fruit St, Boston, MA, 02114 , USA

Tel + I $617643-1425$

Fax + I 617 726-28I4

Email dkeith@mgh.harvard.edu 
Inc. (Houston, TX) TMJ prostheses, and most recently removal of the right total joint prosthesis. Her medical history was relevant for fibromyalgia, for which she was on gabapentin $300 \mathrm{mg}$ three times daily, as well as anxiety and depression, which was treated with bupropion $150 \mathrm{mg}$ once daily, duloxetine $60 \mathrm{mg}$ once daily, and alprazolam $2 \mathrm{mg}$ as needed. She also had a history of a large cutaneous ulcer over the right temporal region which was initially thought to have been caused by a foreign body reaction to the implant material, though an incisional biopsy showed findings consistent with trichotillomania.

Examination revealed right cranial nerve VII deficit, treated with an eyebrow lift, with persistent weakness of the right upper and lower lids of approximately 25-30\%. She had bilateral preauricular swelling and well-healed preauricular and submandibular incisions. Her interincisal range of motion was $14 \mathrm{~mm}$, with a gap of $2 \mathrm{~mm}$ in her maximally closed position. Her pain score was 7/10 intensity using the Visual Analogue Scale (VAS), with her pain reportedly worst in the right jaw. Radiographic examination with both panoramic radiograph and computed tomography (CT) scan showed partial edentulism of the maxilla and mandible. There was a mass of hypertrophic bone in the right TMJ area. The left mandible showed a total joint prosthesis with the condylar component displaced. Figure 1 shows a panoramic radiograph taken at initial consultation.

Over the course of a year, she underwent three separate surgeries: (1) prior embolization of the adjacent right maxillary artery, removal of the right heterotopic bone, removal of the left TMJ prosthesis, bilateral TMJ reconstruction with temporary condylar implants (DuPuy-Synthes, Westchester, PA) and abdominal fat grafts to the dead spaces, (2) removal of the temporary implants and placement of custom-made total TMJ implants (TMJ Implants, Ventura, CA) (3) revision of the left TMJ hardware due to instability. The surgical pathology from each of these surgeries showed evidence of foreign material consistent with retained Proplast-Teflon particles with an associated foreign body giant cell reaction. Following the surgeries, the patient showed significantly improved function with an improved range of motion of $34 \mathrm{~mm}$ mouth opening as well as the ability to fully occlude her teeth. Figure 2 shows a panoramic radiograph following her series of surgeries. Despite the improved ability to open and close her mouth to speak and eat, she reported persistent pain scored as a 7/10 intensity. She also developed synkinesis of the facial muscles, which responded to treatment with tizanidine $2 \mathrm{mg}$ twice daily.

The patient returned three years later with a chief complaint of persistent right-sided pain. Her range of motion was maintained at $35 \mathrm{~mm}$, and her dental occlusion was stable Examination revealed pain on palpation of the right preauricular area and coronoid process. A CT scan revealed no signs of hardware failure. Metal allergy testing for a potential allergy to the prostheses was negative. Serology showed negative rheumatoid factor, antinuclear antibody, and HLA-B27, as well as vitamin D levels

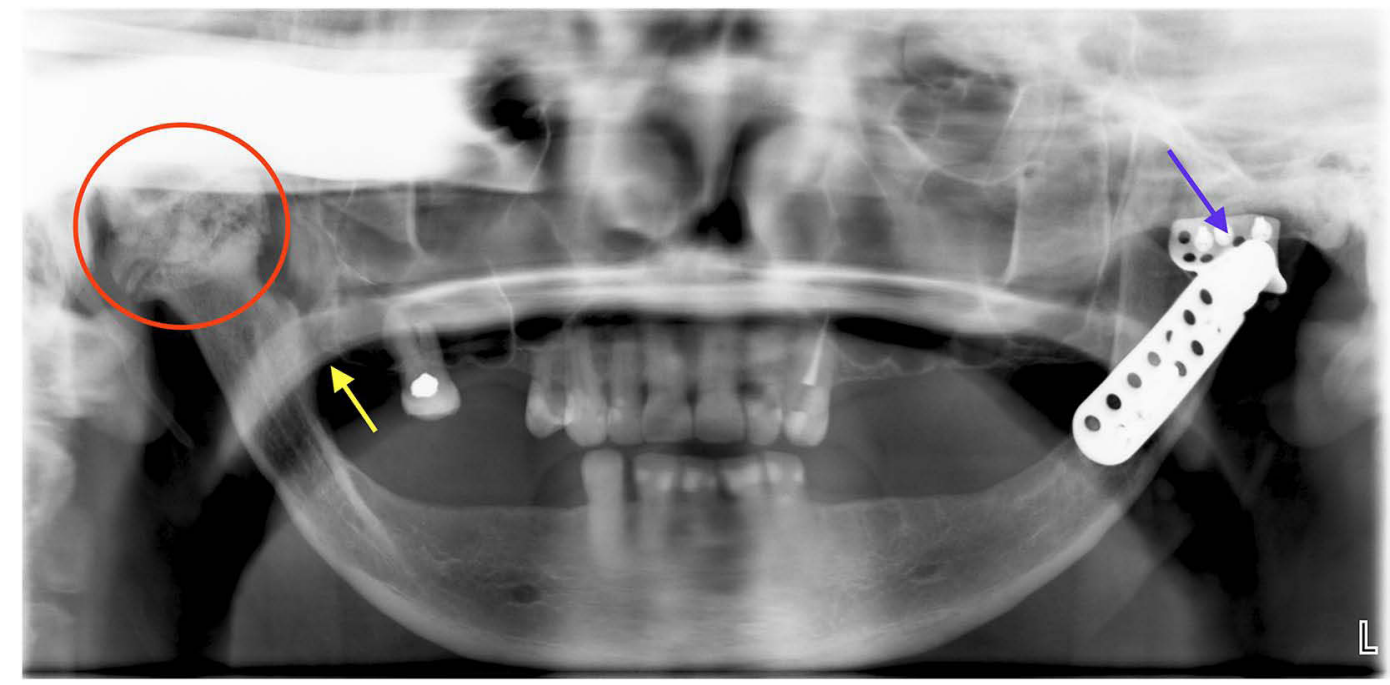

Figure I A panoramic radiograph taken at the time of the patient's initial consultation revealed maxillary and mandibular partial edentulism. On the patient's right side (left side of radiograph), there is an enlarged ankylotic mass fusing the mandible to the right base of the skull (circled in red), with impingement of the right maxillary tuberosity on the anterior aspect of the right mandible (yellow arrow). On the left mandible (right side of radiograph), there is a TMJ prosthetic implant with the mandibular condylar portion dislocated from the glenoid fossa component (blue arrow). Both mandibular coronoid processes are missing, having been surgically removed. The patient's teeth are slightly apart - she can neither fully open nor close her mouth due to the bony fusion. 


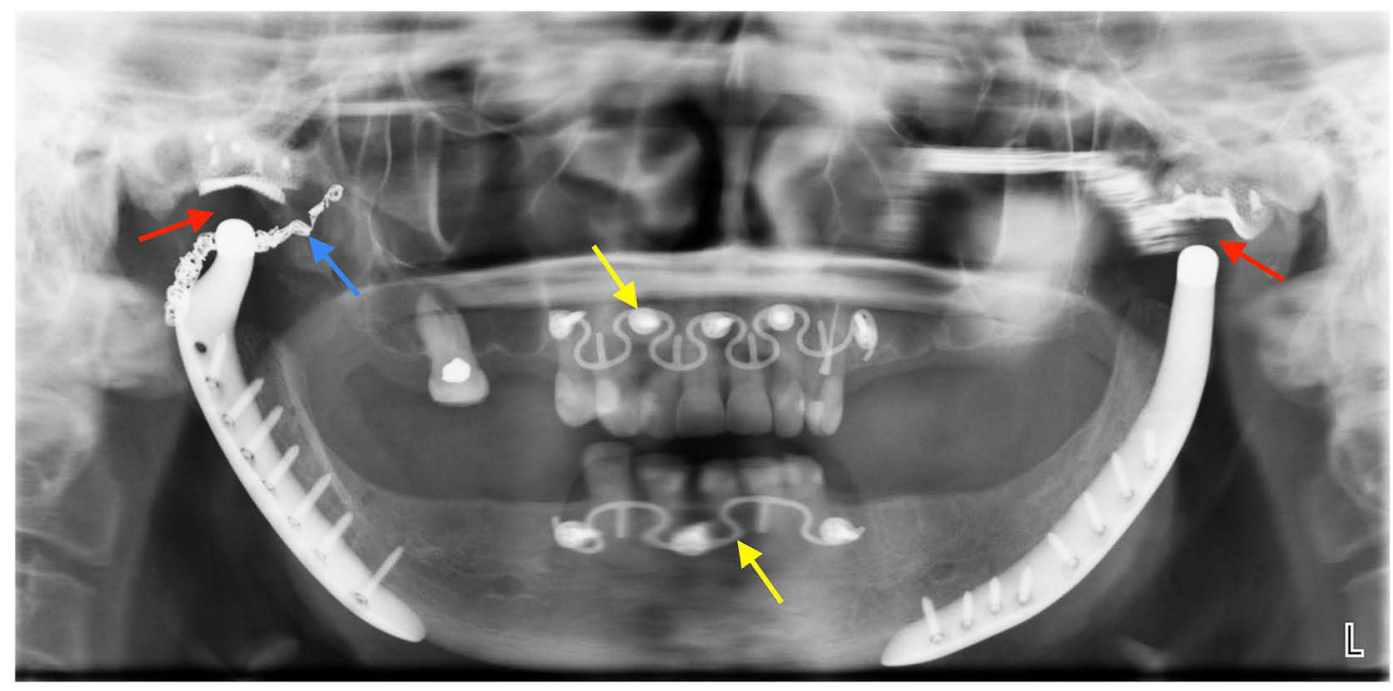

Figure 2 A post-operative panoramic after the patient underwent a series of three separate surgeries to correct her right mandibular bony ankylosis and previously placed failed left TMJ prosthesis. This radiograph depicts bilateral custom-made total TMJ prosthetic implants (TMJ Implants, Ventura, CA). The gaps between the prosthetic condyle and glenoid fossa plate (red arrows) represent the plastic insert on which the metallic condyle articulates. The embolization coil of the right maxillary artery is seen underlying the reconstructed TMJ (blue arrow). Temporary intermaxillary fixation wires are secured with screws (yellow arrows).

within normal limits. Her erythrocyte sedimentation rate and C-reactive protein levels were mildly elevated.

To diagnose and treat her pain, collaborative care between her TMJ surgeon, orofacial pain specialist, and neurologist led to various trials of injection therapy (nerve blocks, trigger point injections, and Botox to the right masticatory muscles) and pharmacotherapy (gabapentin, pregabalin, amitriptyline, baclofen, oxcarbazepine, and lamotrigine). The only treatments that brought her relief were right-sided occipital nerve blocks and right inferior alveolar nerve blocks, which reduced her pain from 7-8/10 down to $4-5 / 10$ intensity for several hours. As part of her comprehensive treatment for chronic pain, she was referred to a pain psychologist; however, after undergoing an initial consultation, the patient declined follow-up care.

Over the course of a year, the patient's pain became more lancinating in nature predominantly in the distribution of the cranial nerve V2 and V3 branches, with pain triggered by touch and cold air, which was concerning for right-sided trigeminal neuralgia. An MRI of her brain revealed no mass lesions or vascular contact leading to compression of the trigeminal nerve. After consultation with a neurosurgeon, she underwent a balloon compression rhizotomy of the right Gasserian ganglion which resolved the lancinating pain.

Following this procedure, she reported a flare of a different type of pain emanating from the right TMJ area. She rated this pain as $8 / 10$ intensity and described it "like a bad ear infection," with pain radiating to "[her] right cheek, sinus, eye, and forehead." She continued on tizanidine $2 \mathrm{mg}$ twice daily, which helped with the muscle pain, as well as baclofen $10 \mathrm{mg}$ three times daily, which reduced pain in the occipital region. She most recently returned to our practice in severe distress with right-sided jaw pain, requesting inpatient admission for pain management and mentioning suicidal thoughts due to her constant pain.

Discussion with her primary care physician (PCP) revealed that she had suffered from chronic pain for the $20+$ years he had known her, with consequences of social isolation and suicidal ideation having been present throughout this time. Her PCP also stated that trials with different anti-depressants had not been helpful in improving her mood or quality of life. Her orofacial pain team confirmed that suicidal ideation had been a recurring theme and that her long clinical course was in part due to her distrust of medical and surgical providers, the failure of multiple attempts to relieve her pain, and the complications that she suffered from each surgical intervention. Consultation with a psychiatrist specializing in chronic pain led to recommendations of long-term psychological support to help her cope with the pain, with an emphasis on helping her understand the neurobiological connection between depression and chronic pain. Her Prescription Drug Monitoring Program data showed that over the past two years, her opioids and benzodiazepines had been predominantly prescribed by her PCP and she had used one pharmacy. Her mean morphine milligram equivalency (MME) was 62 per day, with occasional spikes to $125 \mathrm{MME}$, and her mean lorazepam milligram 
equivalency (LME) was 8.6 per day, with occasional spikes to $17 \mathrm{mg}$ LME.

Ultimately, because she had re-gained a functional range of mandibular motion, no additional surgical intervention was recommended. For pain control, it was recommended that she remain on hydromorphone $2 \mathrm{mg}$ every 4 hours as needed as well as engage in a longitudinal psychiatric program with an emphasis on behavioral health and skills to cope with her pain. The patient agreed that further hospital care would be contingent upon involvement in behavioral health modalities.

\section{The Proplast-Teflon Affair: A 35-Year Retrospective Review Background}

In 1934, Costen, an otolaryngologist, published an article stating that TMJ symptoms were caused by mandibular displacement as a result of missing posterior teeth. ${ }^{9}$ Various iterations of this theory have permeated clinical practice since then and continue to distort our thinking today. Over the following decades, a progressively more scientific approach has been advocated, recognizing the biopsychosocial etiology of these symptoms and the complex nature of these chronic pain conditions, now called temporomandibular disorders. ${ }^{2}$

Originally, our understanding of one of these disorders - the painful clicking and locked jaw - was based on our knowledge of anatomy. With the development of imaging techniques, such as arthrography, computed tomography (CT), and magnetic resonance imaging (MRI), surgeons gained the ability to visualize the meniscus of the TMJ at rest and in motion. ${ }^{10-12}$ These imaging modalities supported the notion of internal derangement of the meniscus as pathology and popularized open joint surgery for meniscal repair or repositioning. Thus, presented with a patient in pain with limited range of motion, an image demonstrating derangement and pathology persuaded oral and maxillofacial surgeons (OMFSs) to contemplate surgical repair, although the rationale of these decisions was suspect. ${ }^{13-15}$ Repositioning of the meniscus became a popular intervention but proved to be unreliable in some cases. ${ }^{16,17}$ Accordingly, starting in the mid-1980s, meniscal replacement came into vogue and a variety of materials were used, including ear cartilage, dura, fascia, temporalis myofascial flaps, metal, Silastic, and ProplastTeflon. ${ }^{16-18}$ It is the PTIPI which is the subject of this review.

\section{The Development of the Proplast Teflon Interpositional Implant}

In 1967, a biochemist named Dr. Charles Homsy was working at DuPont, a chemical and manufacturing company, where he was warned by the company about the dangers of implanted Teflon in the body. ${ }^{19}$ In 1968, he developed a material called Proplast, which he would later patent. Dr. Homsy ultimately left DuPont and founded Vitek, Inc. (VI), a small company located in Texas, to develop, manufacture, and market PTIPIs. Proplast was utilized as it is a porous form of polytetrafluoroethylene (PTFE) that allows for infiltration of soft tissue, thereby stabilizing the implant. Teflon, manufactured by DuPont, is a dense form of PTFE and was added to the TMJ interpositional implant to provide a smooth gliding surface across which the mandibular condyle could move. ${ }^{20}$ Many years prior, in 1963, a British orthopedic surgeon, Dr. John Charnley, warned against the use of PTFE in joints stating, "Surgeons, and especially orthopedic surgeons, should be warned that tissue reactions are likely to follow the implantation of polytetrafluorethylene if this material is subjected to abrasion and that these reactions may not be manifest for two years." In March 1983, VI notified the United States Food and Drug Administration (FDA), which had authority over the use of implantable medical devices, stating that VI was planning to market the PTIPI for the TMJ, based on the claim that it was substantially equivalent to an existing product (silicone sheeting) that was also being used as a TMJ implant. ${ }^{19}$ Its biocompatibility was based on in vitro studies and alveolar ridge augmentation studies. ${ }^{21}$ No animal or biomechanical studies were performed until after its introduction into clinical practice, at which time the adverse effects came to light. The FDA agreed, and the PTIPI was allowed to be marketed. ${ }^{19}$

\section{Clinical Results}

Initially, there were encouraging reports, with success rates estimated in the $90 \%$ range. ${ }^{22-25}$ However, problems were soon reported on the damage that these implants were causing. ${ }^{2,20,26}$ In 1985, Ryan published a series of 105 joints in 67 patients studied for 25 months, finding that patients who originally had no radiographic or surgical evidence of arthrosis developed varying degrees of arthrosis, and those who had had arthrosis developed progression of their disease subsequent to implantation with PTFE-aluminum oxide implants. ${ }^{27}$ In cases of severe arthrosis, MRIs demonstrated loss of signal in the condyle, 
loss of temporal bone, presence of large soft tissue masses, and fragmentation of the implants. At surgery, all implants were found to be perforated, $50 \%$ were folded, and $17 \%$ were fragmented or separated into two components. Four cases demonstrated perforation through the temporal bone with exposure of the dura. Histologic studies of the periimplant tissue yielded exuberant foreign body giant cell reactions with secondary features of chronic inflammation. $^{27}$

In 1987, the US Air Force reported problems to VI and the FDA, and in the following year, the FDA conducted its first inspection of VI. ${ }^{19,28}$ Symptoms including pain, radiographic evidence of severe bone loss in the condyle and glenoid fossa, bite changes, limited jaw motion, joint noises, nausea, dizziness, ringing in the ears, fragmentation and/or displacement of the implant, infection, vision and hearing changes, sinus infections and flu-like symptoms were noted. Subsequently, many papers have documented radiographic changes, pathologic reactions, and clinical symptoms. $^{2-7}$

\section{The Stakeholders}

\section{The Patients}

As no complete registry of patients was maintained, the exact number of patients who had PTIPIs implanted is uncertain. Originally VI stated that 12,500 implants were distributed, but an analysis by the District Court of Dallas indicated that the implants were distributed in packs of two, and on that basis, approximately 26,000 units were manufactured and distributed. ${ }^{29}$ Data from insurance companies showed a disproportionate number of patients who underwent TMJ surgery were young women between 18 44 years of age. ${ }^{1}$ There were also regional differences, with the South being over-represented compared to the Midwest and West/Northeast. Ironically, insurance companies may have contributed to the problem by denying noninvasive treatment modalities for their insureds' TMJ symptoms but covering the surgical procedures.

The clinical consequences of the failure of PTIPIs have become quite apparent. Many of these patients now suffer from chronic pain, mandibular hypomobility, and malocclusion because of multiple surgeries. ${ }^{28,30}$ These symptoms affect their activities of daily living, such as talking, eating, toothbrushing, and receiving regular dental care. Severe limitation of mouth opening may also put them at risk of choking if they require emergency intubation. Other studies have documented the subsequent problems that these patients face when they undergo reconstruction of their damaged TMJs. ${ }^{31}$ From 1984 through 1998, the FDA received 434 adverse event reports for TMJ implants (all types), 58\% of which were associated with patient injuries and $28 \%$ of which were device malfunctions. Over $75 \%$ of these reports cited two manufacturers, Dow Corning and VI - both of which have ceased production of TMJ implants. The most frequent patient problems reported include surgery to remove the implant, pain, foreign body reactions, and loss of range of motion. $^{32}$ A pilot study of surgically retrieved TMJ alloplastic implants similarly demonstrated that pain was a significant symptom associated with perforation of the implants. $^{33}$

Our own review of 95 patients with end-stage TMJ disease that underwent TMJ replacement with total joint prostheses demonstrates clearly that a subset of patients who had a history of failed PTIPI fared less well than those with other diagnoses (for example, ankylosis, inflammatory disease, and trauma). ${ }^{30}$ While on average, the TMJ replacement patients experienced increased range of motion and decreased pain, the subset of 27 patients exposed to PTIPIs was older, had almost twice the number of prior surgeries, had greater limitation of mouth opening prior to surgery, and achieved less range of motion postoperatively, with all of these differences reaching statistical significance. ${ }^{30}$

The general health consequences of these failed implants have also been documented. A non-profit patient advocacy organization, the TMJ Association, has documented patient reports of the presence of flu-like symptoms, chronic sinus infections, skin reactions, local and distant lymphadenopathy, as well as immune system problems. ${ }^{34}$ In 1999, Baird and Rea reported a small series $(n=14)$ of chronically ill, chemically sensitive patients with multisystem end-order disease and labeled this "Implant Syndrome Complex." 35 Severe pain was the predominant symptom, with all of the 3 patients whose histories were described in detail reporting severe pain.

From the patient's perspective, the aftermath of this event was not properly handled. Many complained that they had not been fully informed of the consequences of the implant surgery or that they were unaware of the recall and need for follow-up. When they were seen by their OMFSs, the evaluation was usually limited to a panoramic radiograph, leading to false reassurances that all was well. When they requested their records, oftentimes they were lost or missing due to office fires or flooding. ${ }^{36}$ Patient 
advocacy groups, ${ }^{34}$ newspaper articles, ${ }^{37-39}$ and patient blogs ${ }^{40}$ have also told the story of failed implants, multiple surgeries, and continuing symptoms.

\section{The Manufacturers}

While Dupont manufactured and supplied Teflon for the PTIPI, they played no part in the design, specifications, sales, or distribution of the implants. However, they faced 650 lawsuits by 1500 patients in 42 states in the United States and Canada. ${ }^{41,42}$ In almost all of the US cases, they were found not liable for the safety of the VI product and not considered negligent, as "suppliers of safe multipurpose raw materials have no duty to warn the ultimate consumer of a finished product about dangers that may exist when the raw materials are integrated into the final product.",41

VI, on the other hand, which had manufactured and marketed the PTIPI, was the subject of personal injury lawsuits beginning in $1987 .{ }^{43}$ They successfully defended the first two suits in jury trials and lost the third in late $1989 .^{43}$ The company ultimately declared bankruptcy in 1990. ${ }^{44}$ The founder, Dr. Charles Homsy, fled the US and now lives in Switzerland. He blamed the oral and maxillofacial surgery community and patients for the failure of the implants, and the FDA for its restrictive practices. ${ }^{45}$ In 1991, the FDA seized the remaining implants and buried them in a landfill in Houston, TX. $^{46}$ In 1997, the bankruptcy court settlement with the litigants awarded funds amounting to less than $\$ 10,000$ per patient. ${ }^{47}$ The Judicial Arbitration and Mediation Service/Endispute, Houston reported that 2217 legal claims were made against VI, excluding over 500 who accepted the $\$ 1000$ settlement as final compensation, with a maximum settlement of approximately $\$ 8000$. In reviewing the Referee's Report, the example given provided a settlement of approximately $\$ 2800$ (worth approximately $\$ 4769$ today). $^{47,48}$

One of the VI OMFS consultants conducted animal experiments after the implant failures were reported. The results were "essentially catastrophic." 19 In a letter to Dr. Homsy, he stated that VI might have a "calamity of unbelievable proportions on our hands." 19 The consultant owned 21,000 VI shares and collected royalties and wrote articles praising VI implants, but eventually conceded that the implants had a predicted in vivo life span of only 3 years. $^{49}$

\section{The Food and Drug Administration}

The role of the FDA has been critically evaluated by several authors, ${ }^{45,50}$ and chronologies of these events are available from the FDA among other sources. ${ }^{19,34,51}$ Figure 3 provides a timeline of the initial manufacturing and clinical application of the VI PTIPI and the role of the FDA in regulating its use, as well as scientific literature published on PTIPIs

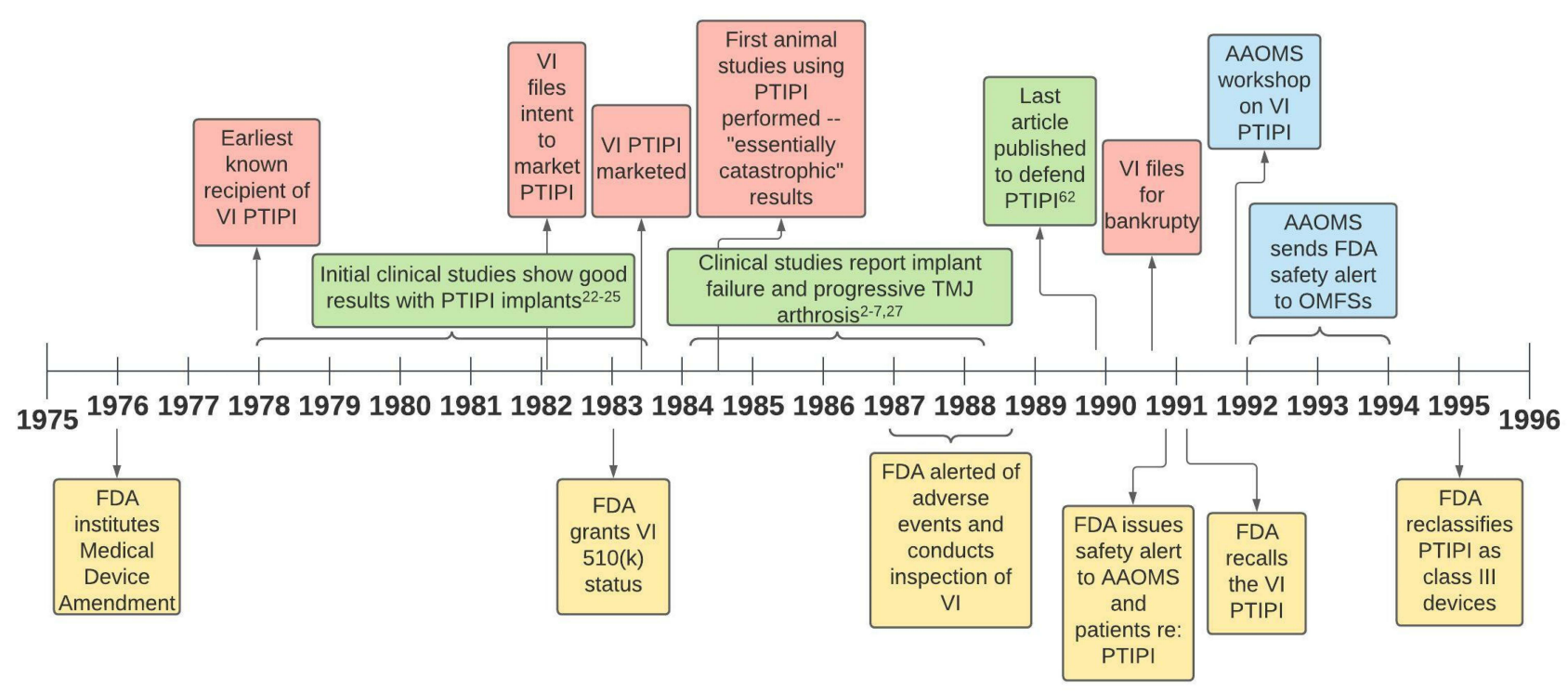

Figure 3 Timeline of events surrounding the manufacturing, clinical use, and ultimate recall of the VI PTIPI. Boxes above the timeline in from VI (red), scientific literature (green), and AAOMS actions (blue). Items below the timeline show FDA regulatory practices (yellow).

Abbreviations: FDA, Food and Drug Administration; VI, Vitek, Inc; PTIPI, Proplast-Teflon interpositional implant; TMJ, temporomandibular joint; AAOMS, American Association of Oral and Maxillofacial Surgeons; OMFS, oral and maxillofacial surgeons. 
throughout the years. Since the 1976 Medical Device Amendments were instituted, the FDA has had jurisdiction over medical devices entering the market. ${ }^{52}$ Despite PTFE having been condemned by Charnley for joints in $1982,{ }^{8} \mathrm{VI}$ filed intent to market PTIPI claiming it to be "substantially equivalent" to Silastic, which was already being used in TMJ surgery. Its biocompatibility was based on in vitro studies and alveolar ridge augmentation studies. ${ }^{21}$ In 1983, FDA notified VI that the IPI is equivalent to devices marketed prior to the FDA's 1976 Medical Device Amendment and granted $510(\mathrm{k})$ premarket notification status. ${ }^{19}$ Later that year, VI initiated commercial distribution of the implants. ${ }^{19}$

In 1987, the US Air Force reported problems to VI and the FDA. ${ }^{19}$ In 1988, the FDA became aware of complaints about the PTIPI implants and explants showing bone resorption, implant fragmentation, and delamination, and as a result, conducted its first inspection of VI. ${ }^{19,51}$ In 1989, the FDA issued VI a regulatory letter for medical device reporting and good manufacturing practices violations. ${ }^{19,51}$ In January 1990, the FDA issued a letter to VI advising it to warn all OMFSs against implanting further devices and monitoring their patients until further clinical data were available. ${ }^{19,51}$ Thus, in March 1990, VI issued a "Dear Doctor" letter to OMFSs, informing them of the hazards associated with the PTIPI product and advising them to closely monitor all patients through clinical and radiographic examination. The FDA classified this action as a voluntary safety alert. ${ }^{51}$ Consequently, VI filed for bankruptcy in June 1990. Shortly thereafter, the FDA issued VI a letter stating that its voluntary safety alert was ineffective, as an audit check had disclosed that some consignees were never notified. ${ }^{51}$ In December 1990, FDA reclassified VI's voluntary status alert to a class I recall and issued a safety alert to all OMFSs, urging them to refrain from using the devices and to return all unused devices to the VI bankruptcy trustee. The FDA also rescinded 510(k) status for VI PTIPI, seized the remaining implants and issued a safety alert to all OMFSs. In 1991, the FDA recalled the VI PTIPI - the first recall for this agency - and issued a medical alert to patients. ${ }^{51}$ The United States Congress held hearings on TMJ implants in $1992 .{ }^{29}$ In 1994, FDA reclassified TMJ Implants as class III devices, subject to premarket approval. ${ }^{51}$

FDA oversight of the PTIPI has been called into question pertaining to several issues. Because TMJ implants were classified as $510(\mathrm{k})$ status, they avoided critical review for several years. There was no system to track the devices, as this was not a component of the FDA inspection process. MedWatch was a voluntary reporting system, and in 1986, reports on VI PTIPI were dismissed. The FDA "seems to have missed several opportunities to intervene and head off the IPI disaster," with one oral surgeon reporting, "The FDA was asleep at the switch."19

In his 1995 Hastings lecture, then FDA Commissioner Dr. David A. Kessler discussed some of the challenges that faced the agency regarding the introduction of medical devices and the role of the FDA "in piloting their path from the bench to the bedside." Citing Shiley heart valves, silicone gel-filled breast implants, and TMJs as examples of problem devices, he explained the several areas for which the FDA was strengthening its activities in product approval, post market surveillance, enforcement, research, and education, noting that "health care practitioners, too, have a responsibility to let us know when they see problems with a device.". 53

\section{The Hospitals}

Dr. Charles Homsy worked at the Methodist Hospital in Houston, Texas, and developed Proplast in a laboratory there. A lawsuit was filed against the hospital in 1994. The suit was settled in 1996 for \$30 million and \$975 million in costs. Individual patients were paid between $\$ 15,000$ and $\$ 100,000$, in addition to $3 \%$ for loss of consortium. $^{43,54}$ The Baylor College of Medicine and the Methodist Hospital were also sued, as tests on components of the PTIPI had been conducted in their facilities and the Methodist Hospital had licensed the manufacture of Proplast to VI. Baylor did not settle and most of the cases were dismissed. ${ }^{43}$

In a review of mass tort cases in 1999 based on published sources, TMJ injury claims that PTIPIs led to fragmentation, pain, and bony and soft tissue damage were compared to claims of damage due to breast implants and orthopedic screws. ${ }^{55}$ PTIPI claims were far fewer than those against manufacturers of breast implants or orthopedic screws, as the total number of estimated exposures was considerably smaller. However, in the case of PTIPI, the cause of damage was highly identifiable. Notably, PTIPI defendants had a low ability to pay following VI filing for bankruptcy, whereas breast and orthopedic screw implant defendants had a higher ability to pay. By 1999, the PTIPI cases were closed, with the other two categories remaining open. The claims to exposure ratio was similar for the PTIPI and orthopedic screw categories, and much higher for the breast implants. 


\section{The Profession}

The American Dental Association (ADA) published the FDA safety warning without comment. $^{56}$ The American Association of Oral and Maxillofacial Surgeons (AAOMS) sent the FDA safety alert, public health advisory, and TMJ implant advisory to members both in 1992 and 1993. ${ }^{57,58}$ However, the organization took no official advisory position. In 1992, the AAOMS held a workshop on the issue, chronicling the history of AAOMS involvement, reviewing the literature, and offering recommendations for managing patients with alloplastic TMJ implants. The workshop furthermore stated that "the recommendations presented represent a consensus of the workshop participants and are not an official statement of AAOMS." 59 AAOMS later published its first document describing the parameters of care in $1992 .^{60}$ Now in its 6 th version, the section on TMJ surgery recognizes "that many patients undergoing TMJ surgeries have unique pain control requirements," and that "this field has undergone a considerable evolution in the past 15-20 years." ${ }^{, 61}$ In regard to alloplastic materials, the document states that "when alloplastics are used, they should be employed following the manufacturer's instructions and consistent with indications approved by the US Food and Drug Administration." 61

In legal disputes, the AAOMS Risk Management group (Oral Surgery National Insurance Company-OMSNIC) defended the profession. At the time, it was headed by an OMFS who had authored an article on 301 patients who had been implanted, and the article blamed the OMFSs and the patients for the implant failures. It was the last article to be published that defended the implant. ${ }^{62}$ Many lawsuits were brought against OMFSs who had implanted the device and were vigorously pursued. ${ }^{63,64}$ Figure 4 shows the premise for each side of the debate.

In one example of a class action suit brought by 21 plaintiffs and 13 spouses, the plaintiffs filed complaints asserting claims of product liability, breach of warranty, negligence, and loss of consortium. Three of the claims were dismissed;

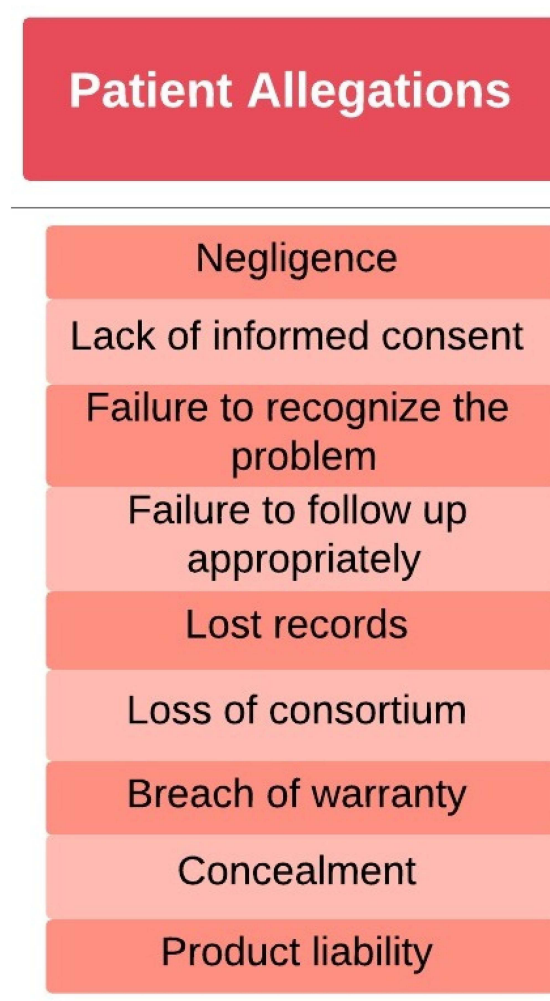

\section{Defense of OMFS}

Implantation of PTIPI
considered standard
practice at the time
Appropriate consent
obtained
Appropriate follow up within
FDA guidelines
Foreign body reactions not
unusual
Lack of consistency in
etiology and rate of PTIPI
breakdown
Lack of consistency in
progression of TMJ
disease

Figure 4 The rationale defending the patient's allegations against Vitek, Inc. Proplast-Teflon interpositional implant (PTIPI) (red) and in defense of oral and maxillofacial surgeons (OMFS) (blue). 
however, negligence both prior and subsequent to the implant surgery was re-evaluated and subsequently hinged on whether the defendants "failed to include as part of their informed consent process before surgery any mention of all the reports of foreign body tissue reactions, bone resorption, immune reaction, or long-term immunological response." 63 After the surgery, the defendants failed "to provide adequate information from which the claimants could make informed judgments about whether and when to have the Vitek implants removed."63 The case languished in the courts and was ultimately dismissed. $^{65}$

The positive and negative results of PTIPI were predominantly published in peer-reviewed OMFS journals. The editor of the Journal of Oral and Maxillofacial Surgery at the time stated that starting in 1986, doctors knew of patients suffering from "extensive resorption of bone and marked tissue inflammation" as well as "intense pain, jaw dysfunction, and occasional changes in the bite." ${ }^{29}$ He reviewed the FDA's response "in the instance of the Teflon/Proplast (Vitek Inc., Houston, TX) fiasco" and concluded "One can no longer use the issue of FDA approval as an excuse if a device eventually proves to be ineffective. ${ }^{, 65}$ In defense of the publication of scientific articles which subsequently turn out to be inaccurate, it can argued that journal editors rely on their reviewers when deciding to publish articles and those views can be biased, ill-informed, or erroneous for a variety of reasons. ${ }^{66}$ Furthermore, it is clear that science changes over time and that our view of scientific authenticity can change as a result of new scientific observations as well as other factors.

\section{Ethics and Innovation in Surgery}

All clinicians are bound by ethical standards that define the framework within which they work. Many articles and guidelines have been published to define these principles, with the four core bioethical principles being respect for patient autonomy, beneficence, non-maleficence, and justice. ${ }^{67,68}$ Embedded within these principles are several items that apply to the PTIPI incident, including: informed consent, truth-telling, good communication skills, ability to exercise sound judgement, research and innovation in surgery, responsible conduct, minimizing harm, recognizing the limitation of one's professional competence, research and auditing, disclosure and discussion of surgical complications including medical errors, and whistle blowing. ${ }^{68}$ A full discussion of each of these points is beyond the scope of this article, although in a statement that speaks more directly to this affair, Adedeji and colleagues wrote, "The surgical profession as a whole has the obligation to improve surgical outcomes and reduce complications by conducting research and participating in systematic programs of quality improvement. This requires keeping detailed and accurate data on the incidence of adverse events." ${ }^{\text {"67 }}$ Adedeji additionally suggests that the burden of proof for any innovative surgical technique lies with the surgeon, who should be prepared to justify such medical decisions to professional colleagues. Establishing these protocols within an ethical framework is the role of Institutional Review Boards which regulate such activities within medical institutions. Several of the principles were seemingly ignored and ethical issues were insufficiently addressed in the PTIPI affair.

\section{Financial Reward}

The issue of financial reward associated with PTIPIs has attracted very little attention. The companies involved in the manufacture and distribution of these implants as well as their officers, shareholders, and consultants were legitimately in the business for financial gain. Likewise, the OMFSs and the hospitals at which they worked expected to be compensated for their efforts to help patients. For OMFSs, it was "a bona fide business opportunity."19 It has been suggested that a conflict of interest existed when oral surgeons owned the implants and were subsequently the distributors, as well as the implanting surgeons. The VI recall notice requested that OMFSs "do not implant any more of these devices if you have any of them in your possession. These implants should be returned for credit. Return these implants to the address below in their original boxes, if available, a copy of the corresponding shipping memorandum."

It has been reported that the chief VI clinical consultant owned less than $1 \%$ of the company's stock and received a royalty payment of $2-4 \%$ of the price of certain products sold, amounting to "about $\$ 50,000$ a year, he says (although Dr. Homsy pegs it closer to $\$ 100,000$ some years)." ${ }^{19}$ Hospitals now have conflict of interest policies to which medical staff and surgeons are expected to abide. These typically contain questions regarding financial interests in pharmaceutical and medical equipment companies.

\section{Root Cause Analysis}

Current thinking about the cause of accidents, adverse events, and near misses in the healthcare field focuses on the several events that need to coincide to create an adverse situation. In any event, hazards exist, and the layers of defense can be breached by latent conditions or active failures, as noted in the "Swiss Cheese model" of failure (Figure 5). ${ }^{70,80}$ In the chain of events leading up to the 


\section{Successive Layers of Defense}

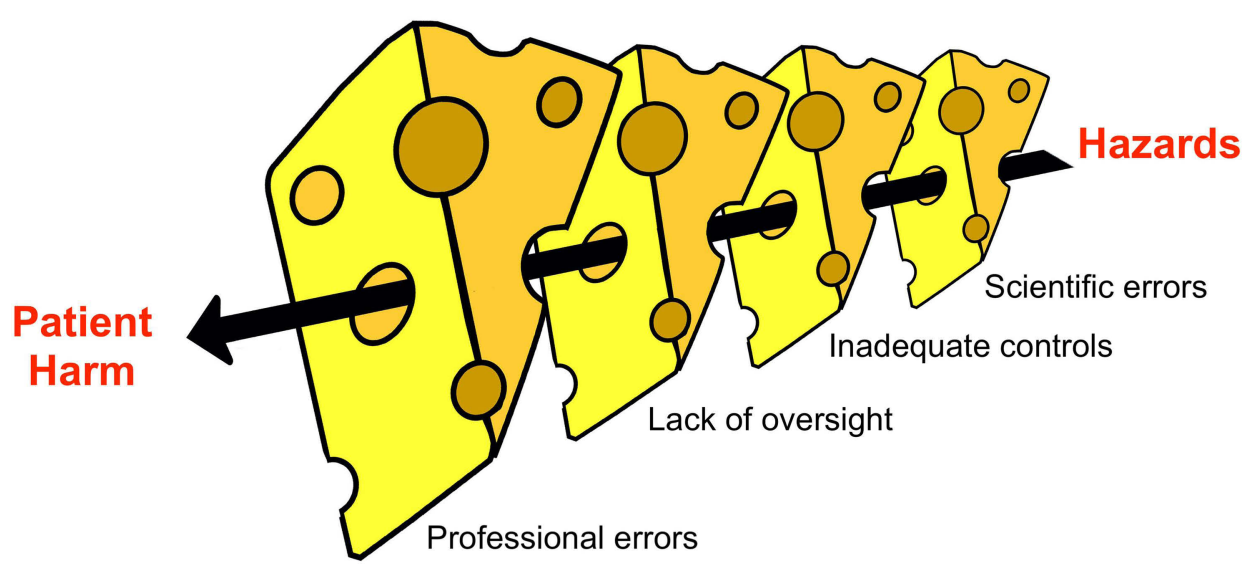

Figure 5 "Swiss cheese" model of failure, proposed and adapted by permission from BMJ Publishing Group Limited. Reason J. Human error: models and management. BMJ. 320,768 , copyright $2020 .{ }^{80}$ In the case of the VI PTIPI, the risk associated with PTIPI managed to pass through "holes" despite layers of defense from the manufacturers, professional societies, hospitals, and the Food and Drug Association.

harm that PTIPIs caused, specifically where were the failures?

Some of the disturbing aspects of the PTIPI incident include the lax regulatory environment at the time, particularly the lack of oversight by manufacturers, such as DuPont, whose products were brought to market by independent companies, such as VI. Importantly, there was a failure of the developers of the PTIPI to recognize or acknowledge the unique features of the TMJ and the empirical literature indicating that this material would fail under loading forces in the joint. In addition, there was a slow and inadequate response of professional organizations, including the AAOMS and ADA, in protecting the public. Furthermore, there was an insistent reliance upon poorly understood technology and an unproven procedure to treat articular disc derangements of the TMJ, which we now know to be a generally self-limiting with a natural history that can resolve over time. ${ }^{71-73}$ The fact that this episode affected a small subspecialty surgical group and a small number of patients, at least in comparison to other implant controversies, in no way mitigates the tragedy of the situation, nor the federal, institutional, and professional responsibilities that were not met.

The contrary view supports the decisions made at the time by the OMFSs involved, based on current knowledge and the imperative to treat patients who were in pain, had dysfunction, and were demanding relief. The legal concept of "standard of care" evolves over time and is generally considered to be "what a minimally competent [surgeon] would do in the same situation, with the same resources,"74 which turns out to be a fairly low bar in this situation. TMJ surgeries represented relatively simple procedures, with doctors describing the procedure with phrases such as, "We'll slip this little disc, and you'll be out of the hospital in two to three days."19 The surgeries often presented an alternative to prolonged and ineffective non-surgical treatment modalities that were either failing to alleviate the symptoms or expensive (for example, extensive orthodontic and/or restorative treatment and orthognathic surgery to provide a "better occlusion"). In addition, indications for surgery were justified by imaging (CT or MRI) that showed derangement or pathology of the TMJ. Thus, it could be said that the failure of the PTIPI was not so much a problem with the implant material as it was with the OMFSs and patients who did not follow instructions. $^{63}$

\section{Conclusion}

In this review, we present a case of a woman who was implanted with a PTIPI in her late 20 s and subsequently developed TMJ destruction with chronic, severe pain of the joint and associated muscles, with associated headaches and neuropathic pain, as well as depression, disability, social isolation, and suicidal ideation. In hindsight, the primary decision to operate was likely flawed, as both the initial surgical procedures and subsequent ones failed to improve her pain or quality of life. The placement of PTIPIs led to worsened pain as well as destruction and ankylosis of her TMJs, likely due to chronic inflammation 
from the Proplast-Teflon particles that disintegrated within the adjacent tissues. While surgery specifically performed to relieve the ankylosis following the placement of PTIPI was successful in improving her range of motion and ability to speak and eat, her pain persisted, unchanged in its intensity. Her persistent pain is likely due to peripheral and central neurological changes associated with chronic inflammation from retained Proplast-Teflon particles, nerve damage, as well as the psychological consequences of her chronic pain. She has since undergone pharmacotherapy with opioid and non-opioid analgesics, injection-based therapies for muscular and neuropathic pain, behavioral therapy, and neurosurgery with a trigeminal ganglion rhizotomy. While some of these treatment modalities were effective (for example, the trigeminal ganglion rhizotomy resolved her sharp, shooting pain in the right mandible), she would ultimately return with symptoms of a different quality of, yet equally severe pain in the head and neck. This case represents one of hundreds of similar patients implanted with PTIPIs who were left with damage to their TMJ as well as complex chronic pain and its psychological effects.

The Proplast-Teflon implant affair is a complex one that involved failures on multiple levels by the manufacturers, the federal agencies overseeing these companies, professional organizations, and individual providers. As such, the PTIPI incident cast a long shadow over TMJ surgery and the OMFSs who chose to treat patients with these conditions. A recent survey of OMFSs lists the PTIPI affair as one of several reasons for not performing TMJ surgery, with one exemplary response stating, "I learned my lesson with Proplast Teflon." ${ }^{, 75}$ The AAOMS has since added language to its standard of care documents specifically related to alloplastic implants. An editorial in the Journal of Oral and Maxillofacial Surgery asks the question, "Does research evidence influence your practice?" and suggests that "the skillful surgeon is also a careful reader." ${ }^{, 76}$ Another editorial stresses the need to "teach and practice evidence-based healthcare and urges OMFS to re-examine the ways each of us practice ... that may not be evidence-based. ${ }^{, 77}$ In response to continued reports of adverse events associated with all types of TMJ implants, the FDA has revised its regulatory and surveillance process to require more rigorous proof of safety and efficacy such that only certain types of total TMJ replacement are available in the United States as compared to worldwide. Consequently, manufacturers in the United States are reluctant to develop different types of prostheses due to the regulatory process and high cost. The FDA also recently updated its website to promote increasing engagement with patients to better understand their symptoms and experience with TMJ surgery with the encouragement of patient advocacy groups. ${ }^{78,79}$

Surgical advances depend on clinical and scientific research, standards of clinical care, and the healthcare and regulatory environment in which outcome improvements can occur. When these factors are either ignored or diminished patient, harm occurs, as demonstrated by the case report presented. The TMJ PTIPI affair is an example that should not be forgotten.

\section{Abbreviations}

TMJ, temporomandibular joint; PTIPI, Proplast-Teflon interpositional implant; OMFS, oral and maxillofacial surgeon; VI, Vitek, Inc.; PTFE, Proplastpolytetrafluoroethylene; FDA, Food and Drug Administration; AAOMS, American Association of Oral and Maxillofacial Surgeons.

\section{Ethics Approval and Consent to Participate}

This project was deemed exempt from the Massachusetts General Hospital's Institutional Review Board as it acknowledged that it did not meet the criteria for human subject research. The patient provided informed consent for the case to be published.

\section{Acknowledgments}

We would like to thank Nathan A. Haskell for his contributions in illustration.

\section{Funding}

This research was supported in part by the Research and Educational Fund, Department of Oral and Maxillofacial Surgery, Massachusetts General Hospital, Boston, MA USA.

\section{Disclosure}

Dr Michael E Schatman is research consultant for Modoscript, outside the submitted work. The authors report no other conflicts of interest in this work.

\section{References}

1. Marbach JJ, Ballard GT, Frankel MR, Raphael KG. Patterns of TMJ surgery: evidence of sex differences. J Am Dent Assoc. 1997;128 (5):609-614. doi:10.14219/jada.archive.1997.0260 
2. Bronstein SL. Retained alloplastic temporomandibular joint disk implants: a retrospective study. Oral Surg Oral Med Oral Pathol. 1987;64(2):135-145. doi:10.1016/0030-4220(87)90079-X

3. McBride KL. Total reconstruction of the temporomandibular joint with the Vitek-Kent prostheses. TMJ Update. 1989;7(1):15-18.

4. Heffez L, Mafee MF, Rosenberg H, Langer B. CT evaluation of TMJ disc replacement with a Proplast-Teflon laminate. J Oral Maxillofac Surg. 1987;45(8):657-665. doi:10.1016/0278-2391(87)90303-X

5. Lagrotteria L, Scapino R, Granston AS, Felgenhauer D. Patient with lymphadenopathy following temporomandibular joint arthroplasty with Proplast. Cranio. 1986;4(2):172-178. doi:10.1080/08869634. 1986.11678143

6. Kaplan PA, Ruskin JD, Tu HK, Knibbe MA. Erosive arthritis of the temporomandibular joint caused by Teflon-Proplast implants: plain film features. AJR Am J Roentgenol. 1988;151(2):337-339. doi:10.2214/ajr.151.2.337

7. Wade MG, Florine D. Assessment of Proplast implants and meniscoplasties as TMJ surgical procedures. Presented at: American Association of Oral and Maxillofacial Surgeons Annual Meeting; 1986; New Orleans, LA.

8. Charnley J. Tissue reaction to the polytetrafluoroethylene. Lancet. 1963;2:1379. doi:10.1016/S0140-6736(63)90759-1

9. Costen JB. A syndrome of ear and sinus symptoms dependent upon disturbed function of the temporomandibular joint. 1934. Ann Otol Rhinol Laryngol. 1997;106(10 Pt 1):805-819. doi:10.1177/ 000348949710601002

10. Norgaard F; Norgaard. Arthrography of the mandibular joint. Acta Radiol. 1944;25(5-6):679-685. doi:10.3109/00016924409136498

11. Wilkes $\mathrm{CH}$. Arthrography of the temporomandibular joint in patients with the TMJ pain-dysfunction syndrome. Minn Med. 1978;61 (11):645-652.

12. Manzione JV, Katzberg RW, Brodsky GL, Seltzer SE, Mellins HZ. Internal derangements of the temporomandibular joint: diagnosis by direct sagittal computed tomography. Radiology. 1984;150 (1):111-115. doi:10.1148/radiology.150.1.6689751

13. Stohler CS, Zarb GA. On the management of temporomandibular disorders: a plea for a low-tech, high-prudence therapeutic approach. J Orofac Pain. 1999;13(4):255-261.

14. Greene C. The relationship between pain, pathology, and surgery in the treatment of temporomandibular disorders. In: Keith D, editor. Surgery of the Temporomandibular Joint. Blackwell Scientific; 1988:255-261.

15. Dolwick MF. Intra-articular disc displacement. Part I: its questionable role in temporomandibular joint pathology. J Oral Maxillofac Surg. 1995;53(9):1069-1072. doi:10.1016/0278-2391(95)90126-4

16. McCarty WL, Farrar WB. Surgery for internal derangements of the temporomandibular joint. J Prosthet Dent. 1979;42(2):191-196. doi:10.1016/0022-3913(79)90174-4

17. Conway WF, Hayes CW, Campbell RL, Laskin DM, Swanson KS. Temporomandibular joint after meniscoplasty: appearance at MR imaging. Radiology. 1991;180(3):749-753. doi:10.1148/radiology.180.3. 1871289

18. De Meurechy N, Mommaerts MY. Alloplastic temporomandibular joint replacement systems: a systematic review of their history. Int J Oral Maxillofac Surg. 2018;47(6):743-754. doi:10.1016/j. ijom.2018.01.014

19. Ingersoll BG, Medical Mess: R. Implants in Jaw Joints Fail, Leaving Patients In Pain And Disfigured. Wall Street J. 1993;31(A1):A6.

20. Ryan DE. Alloplastic implants in the temporomandibular joint. Oral Maxillofac Surg Clin North Am. 1989;1:427.

21. Kent JN, Westfall RL, Carlton DM. Chin and zygomaticomaxillary augmentation with Proplast: long-term follow-up. J Oral Surg. 1981;39(11):912-919.

22. Dusek JK, Kent JH, Smith P Proplast Teflon implants for treatment of TMJ degenerative disease. Presented at: American Association of Oral and Maxillofacial Surgeons Annual Meeting; 1978; Chicago, Illinois.
23. Malloy RB, Kent JH, Smith P, Staple H The treatment of arthrosis with Proplast-Teflon implants. Presented at: American Association of Oral Maxillofacial Surgeons Annual Meeting; 1981; Washington, D.C.

24. Kiersch T The use of Proplast Teflon implants for meniscectomy and disc repair in the temporomandibular joint. Presented at: International Conference on Oral Surgery; Berlin, Germany; 1984.

25. Vitek, Inc. Notice to Oral and Maxillofacial Surgeons: Important Information on Temporomandibular Joint Surgery. Houston, TX: Vitek, Inc; 1986.

26. Wagner JD, Mosby EL. Assessment of Proplast-Teflon disc replacements. J Oral Maxillofac Surg. 1990;48(11):1140-1144. doi:10.1016/0278-2391(90)90528-A

27. Ryan DE. Anterior open bite in $20 \%$ and occasional continued degeneration of the condyles. In: Temporomandibular Joint Newsletter. Medical College of Wisconsin; 1985:3.

28. Mendenhall S TMJ Implants: lessons for all of us. orthopedic network news (ONN): trauma Update; 1995. Available from: https:// curvolabs.com/insights/tmj-implants-lessons-for-all-of-us/. Accessed July $9,2021$.

29. Are FDA and NIH Ignoring the Dangers of TMJ (Jaw) Implants?: Hearing before the Subcommittee on Human Resources and Intergovernmental Relations of the Committee on Government Operations, 102nd Congress. 1992.

30. Sahdev R, Wu BW, Anderson N, et al. Study of patient outcomes after temporomandibular joint replacement with alloplastic total joint prosthesis at Massachusetts general hospital. J Oral Maxillofac Surg. 2019;77(2):280-288. doi:10.1016/j.joms.2018.09.002

31. Henry CH, Wolford LM. Treatment outcomes for temporomandibular joint reconstruction after Proplast-Teflon implant failure. $J$ Oral Maxillofac Surg. 1993;51(4):352. doi:10.1016/S0278-2391(10)80343-X

32. United States Food and Drug Administration. Manufacturer and User Facility Device Experience (MAUDE) Adverse Event Report; TMJ Implants (1948 to 1998). United States Food and Drug Administration; 1999.

33. Ferreira JN, Ko CC, Myers S, Swift J, Fricton JR. Evaluation of surgically retrieved temporomandibular joint alloplastic implants: pilot study. J Oral Maxillofac Surg. 2008;66(6):1112-1124. doi:10.1016/j.joms.2007.09.013

34. TMJ Association [homepage on the Internet]. Milwaukee, WI: The TMJ Association, Ltd; 2021. Available from: https://tmj.org/. Accessed July 9, 2021.

35. Baird DN. The temporomandibular joint implant controversy: a review of autogenous/alloplastic materials and their complications. $J$ Nutrition Environ Med. 1998;8:289-300. doi:10.1080/13590849862078

36. Keith DA. Personal communication from patients re: request for previous records. 2017.

37. Pope J. Amy's Pain. The Times Picayune; 1993:A1, A18.

38. Foreman J. Danger cited in Teflon jaw implants. Boston Globe. 1992;1:11.

39. Deane B. The TMJ Implant Disaster. Women's Day. 1983;1:38-45.

40. TMJ Patient Stories. TMJ Hope [homepage on the Internet]. Available from: www.tmjhope.org/category/blog/tmj-patient-stories/. Accessed July 7, 2021.

41. In re: temporomandibular Joint (TMJ) Implants Products Liability Litigation, (United States Court of Appeals, Eighth Circuit 1996). Available from: https://caselaw.findlaw.com/us-8th-circuit/1182895. html. Accessed July 9, 2021.

42. Makin K Jaw-implant class action given the go-ahead. The Globe and Mail; 2007. Available from: https://www.theglobeandmail.com/news/ national/jaw-implant-class-action-given-the-go-ahead/arti cle20401634/. Accessed July 9, 2021.

43. Homsy C. How FDA regulation and injury litigation cripple the medical device industry. Policy Analysis. Cato Institute; 2001; 412. Available from: https://object.cato.org/sites/cato.org/files/pubs/pdf/ pa412_1.pdf. Accessed July 9, 2021. 
44. Beachy D. Houston firm recalls jaw joint implants - Patients with Vitek devices urged to get examination for bone deterioriation. Houston Chronicle. 1991;3:58.

45. Christensen RW, Pilot LM, Homsy LR. FDA, You Were Wrong!: Stopping Innovation, Stops America! Mustang, OK: Tate Publishing \& Enterprises; 2012.

46. Beachy D. Figure in jaw implant case now in Switzerland. Houston Chronicle. 1993;1:254.

47. Referee's Report In Re: Vitek, Inc. Employer I.D. No.74-1658060 Debtor (United States Bankruptcy Court for the Southern District of Texas - Houston Division 1993).

48. Trustee's Motion for Authority to Establish Designated Settlement Fund In Re: Vitek, Inc. Employer I.D. No.74-1658060 Debtor (United States Bankruptcy Court for the Southern District of Texas - Houston Division 1991)

49. Fontenot MG, Kent JN. In vitro wear performance of Proplast TMJ disc implants. J Oral Maxillofac Surg. 1992;50(2):133-139. doi:10.1016/0278-2391(92)90358-7

50. Grushka K. Proplast-Teflon Jaw Implants and FDA Review Standards for Medical Devices: a Case Study [dissertation]. Michigan State University College of Agriculture and Natural Resources; 2006. Available from: https://www.canr.msu.edu/iflr/ uploads/files/Student\%20Papers/Grushka.Finalpaper.pdf. Accessed July 9, 2021.

51. TMJ Implants: a Consumer Information Update [homepage on the Internet]. Washington, D.C: United States Food and Drug Administration; 2021. Available from: https:/www.fda.gov/medicaldevices/temporomandibular-disorders-tmd-devices/temporomandibu lar-joint-tmj-implants. Accessed July 9, 2021.

52. Medical Device Amendments. Public Law No. 94-295(1976). Available from: https://www.gpo.gov/fdsys/pkg/STATUTE-90/pdf/ STATUTE-90-Pg539.pdf. Accessed July 9, 2021.

53. Kessler DA. Hastings lecture, December 10, 1993, Rockville, Maryland, U.S.A. Artif Organs. 1994;18(10):718-724. doi:10.1111/ j.1525-1594.1994.tb03308.x

54. Baird J. Methodist will pay $\$ 30$ million to settle jaw implant claims. Houston Chronicle. 1995;1:254.

55. Spiro R, Witcher C, Egelston P, Hruby S, Deckman Fallon M, Willging $\mathrm{M}$ Individual characteristics of mass torts case congregations: a report to the mass torts working group. administrative office of the United states courts; 1999. Available from: https://www. uscourts.gov/file/document/individual-characteristics-mass-torts-case -congregations-appendix-d-report-mass-torts. Accessed July 9, 2021.

56. Frodel J. FDA urges removal of proplast implants. J Am Dent Assoc. 1992;123(4):22.

57. Implant Advisory News. In: AAOMS Fellows Members, Affiliates, Life Members, and Candidates. American Association of Oral and Maxillofacial Surgery - Board of Trustees; 1992.

58. Important News from AAOMS. AAOMS Fellows Members, Affiliates, Life Members, and Candidates. American Association of Oral and Maxillofacial Surgery - Board of Trustees; 1993.

59. Ness G. Recommendations for management of patients with temporomandibular joint implants. Temporomandibular Joint Implant Surgery Workshop. J Oral Maxillofac Surg. 1993;51 (10):1164-1172. doi:10.1016/S0278-2391(10)80464-1

60. Parameters of care for oral and maxillofacial surgery. A guide for practice, monitoring and evaluation (AAOMS Parameters of Care-92). American Association of Oral and Maxillofacial Surgeons. J Oral Maxillofac Surg. 1992;50(7Suppl 2):i-xvi, 1-174.

61. Bouloux G, Koslin MG, Ness G, Shafer D. Temporomandibular Joint Surgery. J Oral Maxillofac Surg. 2017;75(8S):e195-e223.
62. Estabrooks LN, Fairbanks CE, Collett RJ, Miller L. A retrospective evaluation of 301 TMJ Proplast-Teflon implants. Oral Surg Oral Med Oral Pathol. 1990;70(3):381-386. doi:10.1016/0030-4220(90)90164-N

63. Patricia Brawn et al v Oral Surgery Associates et al, (Supreme Judicial Court of Maine 2003). Available from: https://aw.justia. com/cases/maine/supreme-court/2003/03me11abr.html. Accessed July 9, 2021.

64. Welch v. McCarthy, (Supreme Judicial Court of Maine 1996). Available from: https://law.justia.com/cases/maine/supreme-court /1996/677-a-2d-1066-0.html. Accessed July 9, 2021.

65. Laskin DM. Shifting the responsibility for medical decisions. J Oral Maxillofac Surg. 2001;59(6):601-602. doi:10.1053/joms.2001.24812

66. Wiley Publishing. Working with Editors. John Wiley \& Sons, Inc. Available from: https://authorservices.wiley.com/Reviewers/journalreviewers/how-to-perform-a-peer-review/work-with-editors.html. Accessed July 7, 2021.

67. Adedeji S, Sokol DK, Palser T, McKneally M. Ethics of surgical complications. World J Surg. 2009;33(4):732-737. doi:10.1007/ s00268-008-9907-z

68. Beauchamp TC. Principles of Biomedical Ethics. 8th ed. Oxford University Press; 2019.

69. Vitek, Inc. Voluntary Safety Alert. Sent to OMFS. Houston, TX: Vitek, Inc; 1990

70. Reason J. The contribution of latent human failures to the breakdown of complex systems. Philos Trans R Soc Lond B Biol Sci. 1990;327 (1241):475-484.

71. Schiffman EL, Look JO, Hodges JS, et al. Randomized effectiveness study of four therapeutic strategies for TMJ closed lock. J Dent Res. 2007;86(1):58-63. doi:10.1177/154405910708600109

72. Dodson TB. TMJ closed lock symptoms improve, regardless of intervention. $J$ Evid Based Dent Pract. 2008;8(1):19-21. doi:10.1016/j.jebdp.2007.12.005

73. Schiffman EL, Velly AM, Look JO, et al. Effects of four treatment strategies for temporomandibular joint closed lock. Int J Oral Maxillofac Surg. 2014;43(2):217-226. doi:10.1016/j. ijom.2013.07.744

74. Moffett P, Moore G. The standard of care: legal history and definitions: the bad and good news. West J Emerg Med. 2011;12 (1):109-112.

75. Mercuri LG. Temporomandibular joint disorder management in oral and maxillofacial surgery. J Oral Maxillofac Surg. 2017;75 (5):927-930. doi:10.1016/j.joms.2016.10.033

76. Assael LA. Evidence-based practice: what does it really mean? J Oral Maxillofac Surg. 2008;66(10):1979-1980. doi:10.1016/j. joms.2008.08.001

77. Hupp JR. Evidence-based practice: research opportunities. J Oral Maxillofac Surg. 2017;75(5):881-882. doi:10.1016/j. joms.2017.03.001

78. Temporomandibular Joint (TMJ) Implants. Washington, D.C: United States Food and Drug Administration; 2021. Available from: https:// www.fda.gov/medical-devices/temporomandibular-disorders-tmddevices/temporomandibular-joint-tmj-implants\#reports. Accessed July 9, 2021.

79. Crowley T. Medical Devices - Patient Engagement in Real World Evidence (RWE): lessons Learned and Best Practices. Presented at: University of Maryland Center of Excellence in Regulatory Science and Innovation (M-CERSI), the Center on Drugs and Public Policy (CDPP) at the University of Maryland School of Pharmacy, and the Center for Devices and Radiological Health $(\mathrm{CDRH})$ at the Food and Drug Administration (FDA); 2018 Sept 12; Baltimore, MD.

80. Reason J. Human error: models and management. BMJ. 2000;320:768. doi:10.1136/bmj.320.7237.768 
Journal of Pain Research

Dovepress

\section{Publish your work in this journal}

The Journal of Pain Research is an international, peer reviewed, open access, online journal that welcomes laboratory and clinical findings in the fields of pain research and the prevention and management of pain. Original research, reviews, symposium reports, hypothesis formation and commentaries are all considered for publication. The manuscript management system is completely online and includes a very quick and fair peer-review system, which is all easy to use. Visit http:// www.dovepress.com/testimonials.php to read real quotes from published authors.

Submit your manuscript here: https://www.dovepress.com/journal-of-pain-research-journal 